\title{
First-in-human radiofrequency ablation of ventricular tachycardia performed through an Atrial Flow Regulator device
}

\author{
Mateusz Wilkowski ${ }^{1 *}$, Łukasz Lewicki ${ }^{2}{ }^{3 *}$, Rafał Olszewski ${ }^{1}$, Adam Priebe $^{3}$, \\ Miłosz J. Jaguszewski ${ }^{4}$, Marek Szołkiewicz ${ }^{3}$ \\ ${ }^{1}$ Department of Cardiology St. Wojciech Hospital COPERNICUS, Gdansk, Poland \\ ${ }^{2}$ University Center for Cardiology, Gdansk, Poland \\ ${ }^{3}$ Department of Cardiology and Angiology, Kashubian Center for Heart and Vascular Diseases, \\ Pomeranian Hospitals, Wejherowo, Poland \\ ${ }^{4}$ First Department of Cardiology, Medical University of Gdansk, Poland
}

\section{This paper was guest edited by Prof. Marek Grygier}

Despite substantial progress in electrotherapy, sustained ventricular tachycardia (VT) and electrical storm remain the frequent causes of death among patients with end-stage heart failure (HF). A radiofrequency ( $R F$ ) ablation ( $R F A)$ is a wellrecognized treatment option for patients with electrical storm who suffer from resistant VT [1].

Recently we published the clinical and hemodynamic results of a 66 -year-old patient with $\mathrm{HF}$, left ventricular ejection fraction $20 \%$, who underwent a novel therapy based on atrial septostomy followed by implantation of the Atrial Flow Regulator (AFR, Occlutech, Helsingborg, Sweden) [2]. Six weeks after AFR implantation, the patient was hospitalized because of recurrent VT with multiple appropriate cardioverter-defibrillator (ICD) shocks. On admission, the patient was conscious and hemodynamically stable. He was taking beta-blocker and amiodarone for an extended period before recent hospitalization. During the patient's stay in the intensive care unit, a basic pacing rhythm was increased to $100 / \mathrm{min}$, and continuous infusion of lignocaine up to $120 \mathrm{mg}$ per hour was started. The patient received sedation, however, sustained VT recurred during the following couple of days. Therefore, a decision was made to perform an electrophysiological study followed by RFA.
The procedure was done on $4^{\text {th }}$ of March 2020.

Under local anesthesia and sedation with remifentanil and midazolam, right femoral vein access was obtained. A 0.032 guidewire was placed into the left atrium through the $8 \mathrm{~mm}$ fenestration in the AFR device in the first step. Steerable sheath (Agilis NxT large curve) was introduced into the left atrium using the $8 \mathrm{~mm}$ hole (Fig. 1). The procedure was performed using the Ensite Precision three-dimensional mapping system (Abbott Cardiovascular). Substrate mapping and ablation of conductive channels within the scar approach was planned. During right ventricle pacing from implanted ICD, a potential bipolar map was obtained with an HDGrid catheter. An extensive scar of the anterior wall, including the anterior part of the septum and apex, was mapped. Also, low and late potentials were found, especially in the apex and mid anterior wall (Fig. 1). During catheter manipulation, clinical arrhythmia was easily induced. Because of acceptable tolerance, an activation map during VT was also obtained, revealing the exit of the VT loop in the mid-region of the anterior wall. Pacing within the scar of this site resulted in S-QRS $150 \mathrm{~ms}$ with $90 \%$ QRS morphology concordance. HDGrid mapping catheter was exchanged to TactiCath SE F-J ablation catheter, and RF applications in this region (50 W $30 \mathrm{~s}$ ) was applied. Rapid ventricular

Address for correspondence: Łukasz Lewicki, MD, PhD, University Center for Cardiology, ul. Dębinki 2, 80-211 Gdańsk, Poland, tel: +48501702 885, e-mail: luklewicki@gmail.com

Received: $22.11 .2020 \quad$ Accepted: 24.11 .2020

* The first two authors contributed equally to this work.

This article is available in open access under Creative Common Attribution-Non-Commercial-No Derivatives 4.0 International (CC BY-NC-ND 4.0) license, allowing to download articles and share them with others as long as they credit the authors and the publisher, but without permission to change them in any way or use them commercially. 


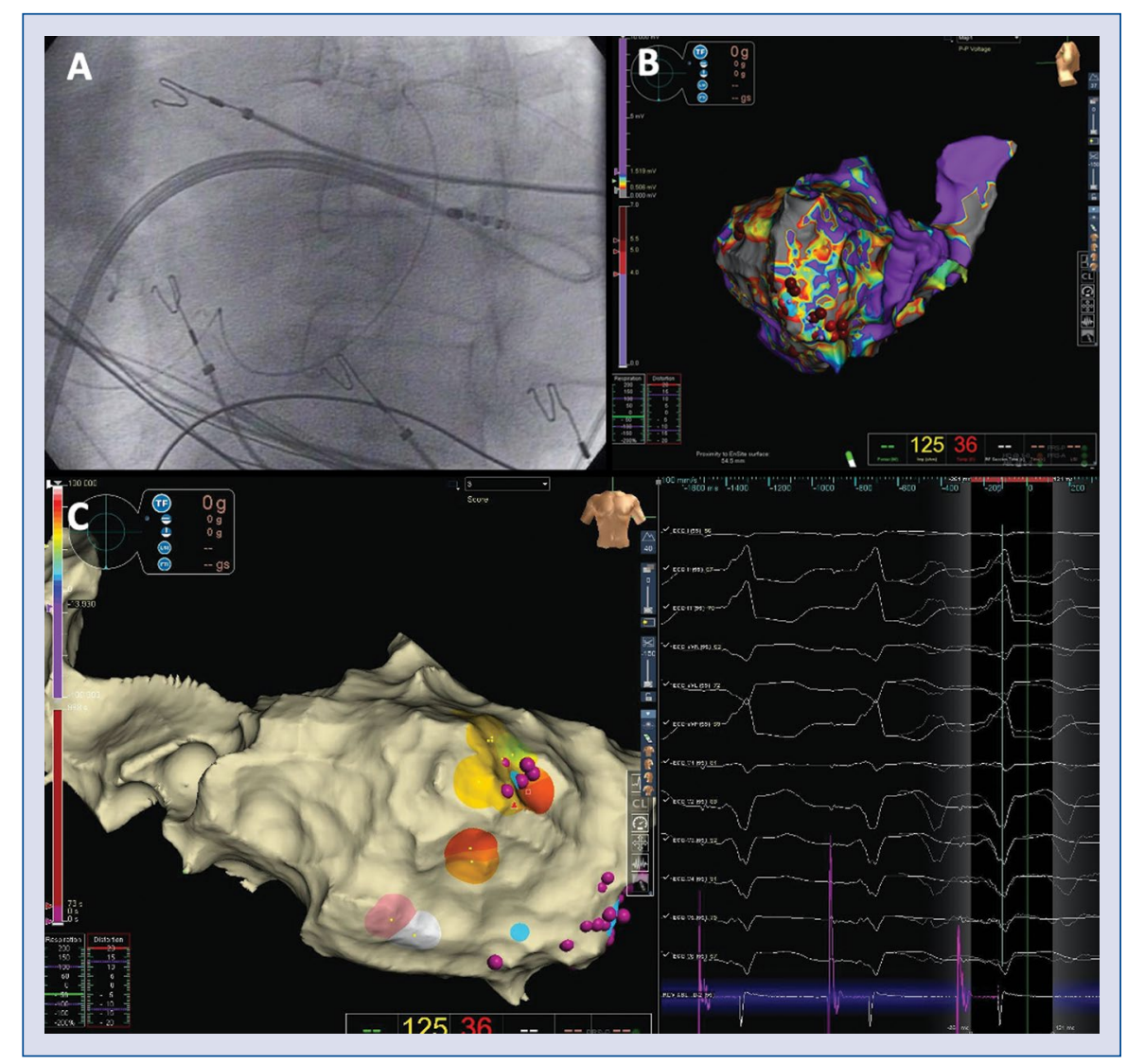

Figure 1. A. Left anterior oblique 30 view of the steerable sheath with the ablation electrode introduced through Atrial Flow Regulator device; B. Bipolar map of the extensive anterior wall, septum, and apical scar with patchy areas in apex and late potentials recorded in this region; C. Long S-QRS interval during anterior part of septum stimulation (capture of conducting channel in a scar) with similar to ventricular tachycardia paced QRS morphology.

stimulation-induced another VT with a loop exiting scar in the apical region. $\mathrm{RF}$ applications ( $55 \mathrm{~W}$ $30 \mathrm{~s}$ ) resulted in the abolition of late potentials in this area and the arrhythmia's non-inducibility.

The patient was discharged home on the third day after the procedure. He remained free of ventricular arrhythmia during 3 months follow-up.

The AFR is a self-expandable double-disc nitinol wire mesh construction allowing communication across the interatrial septum through an $8 \mathrm{~mm}$ fenestration. This communication enables the decompression of the left atrium and may improve patients' symptoms [3].

We have successfully implanted ten AFR devices thus far in patients with severe HF. These procedures were done as part of an ongoing PROLONGER trial (Pomeranian atRial flOw reguLatOr iN conGestive hEart failuRe; No. NCT04334694 at clinicaltrials.gov). According to available research, this is the first published data on performing an
RFA in a patient with an electrical storm using a fenestration in AFR.

Conflict of interest: None declared

\section{References}

1. Muser D, Liang JJ, Santangeli P. Electrical storm in patients with implantable cardioverter-defibrillators: a practical overview. J Innov Card Rhythm Manag. 2017; 8(10): 2853-2861, doi: 10.19102/ icrm.2017.081002, indexed in Pubmed: 32477756.

2. Lewicki $\succeq$, Sabiniewicz R, Siebert J, et al. Atrial flow regulator as a novel therapy for patients with chronic heart failure. Cardiol J. 2020; 27(3): 309-311, doi: 10.5603/CJ.a2020.0077, indexed in Pubmed: 32436584.

3. Paitazoglou C, Özdemir R, Pfister R, et al. The AFR-PRELIEVE trial: a prospective, non-randomised, pilot study to assess the Atrial Flow Regulator (AFR) in heart failure patients with either preserved or reduced ejection fraction. EuroIntervention. 2019; 15(5): 403-410, doi: 10.4244/EIJ-D-19-00342, indexed in Pubmed: 31130524. 